\title{
Corrigendum: Arabidopsis Fructokinases Are Important for Seed Oil Accumulation and Vascular Development
}

\begin{abstract}
Ofer Stein ${ }^{1,2}$, Tamar Avin-Wittenberg ${ }^{3,4}$, Ina Krahnert ${ }^{3}$, Hanita Zemach ${ }^{1}$, Vlada Bogol ${ }^{1}$, Oksana Daron ${ }^{5}$, Roni Aloni ${ }^{6}$, Alisdair R. Fernie ${ }^{3}$ and David Granot ${ }^{1 *}$

${ }^{1}$ Volcani Center, Institute of Plant Sciences, Agricultural Research Organization, Beit Dagan, Israel, ${ }^{2}$ Robert H. Smith Faculty of Agriculture, Institute of Plant Sciences and Genetics in Agriculture, Food and Environment, Hebrew University of Jerusalem, Rehovot, Israel, ${ }^{3}$ Max-Planck-Institut für Molekulare Pflanzenphysiologie, Potsdam-Golm, Germany, ${ }^{4}$ Department of Plant and Environmental Sciences, Hebrew University of Jerusalem, Givat Ram, Jerusalem, Israel, ${ }^{5}$ Department of Life Sciences, Ben-Gurion University, Beer-Sheva, Israel, ${ }^{6}$ Department of Plant Sciences, Tel Aviv University, Tel Aviv, Israel
\end{abstract}

Keywords: fructokinase, seed oil, xylem, fatty acid, carbon metabolism

\section{A corrigendum on}

Arabidopsis Fructokinases Are Important for Seed Oil Accumulation and Vascular Development

by Stein, O., Avin-Wittenberg, T., Krahnert, I., Zemach, H., Bogol, V., Daron, O., et al. (2017). Front. Plant Sci. 7:2047. doi: 10.3389/fpls.2016.02047

\section{ERROR IN FIGURE 1}

In the original article, there was a mistake in Figure $\mathbf{1}$ as published. The gene ID for AtFRK3 and AtFRK4 that were used in the mega4 software for creating the phylogenetic tree were incorrect. AtFRK3 (At3g59480) should read AtFRK3 (At1g06020) and AtFRK4 (At4g06030) should read AtFRK4 (At3g59480) as in the text, Table S1 and uniprot annotation for arabidopsis probable fructokinases. The corrected Figure $\mathbf{1}$ appears below. The authors apologize for this error and state that this does not change the scientific conclusions of the article in any way.

\section{REFERENCES}

Received: 08 February 2017 Accepted: 20 February 2017

Published: 06 March 2017

Citation:

Stein O, Avin-Wittenberg T, Krahnert I, Zemach H, Bogol V, Daron O, Aloni R, Fernie AR and Granot D (2017)

Corrigendum: Arabidopsis Fructokinases Are Important for Seed Oil Accumulation and Vascular Development. Front. Plant Sci. 8:303. doi: 10.3389/fp/s.2017.00303
Tamura, K., Dudley, J., Nei, M., and Kumar, S. (2007). MEGA4: Molecular Evolutionary Genetics Analysis (MEGA) software version 4.0. Mol. Biol. Evol. 24, 1596-1599. doi: 10.1093/molbev/msm092

Conflict of Interest Statement: The authors declare that the research was conducted in the absence of any commercial or financial relationships that could be construed as a potential conflict of interest.

Copyright (C) 2017 Stein, Avin-Wittenberg, Krahnert, Zemach, Bogol, Daron, Aloni, Fernie and Granot. This is an open-access article distributed under the terms of the Creative Commons Attribution License (CC BY). The use, distribution or reproduction in other forums is permitted, provided the original author(s) or licensor are credited and that the original publication in this journal is cited, in accordance with accepted academic practice. No use, distribution or reproduction is permitted which does not comply with these terms. 


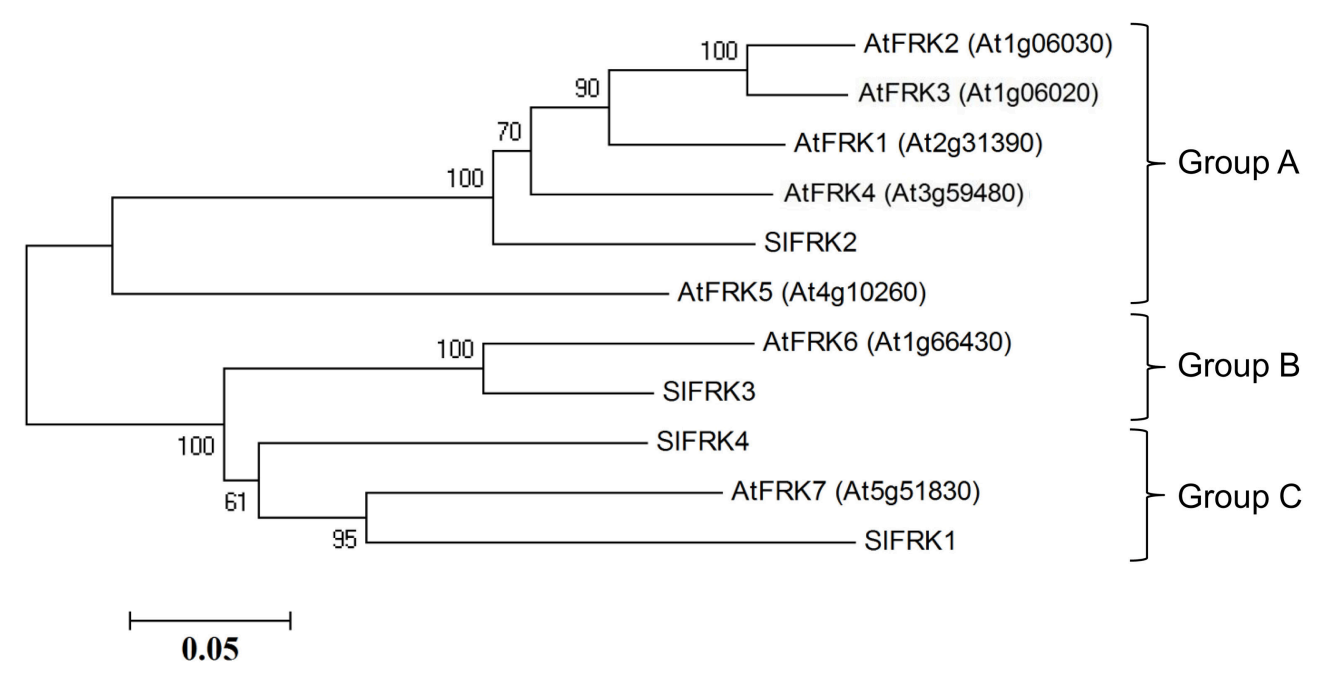

FIGURE 1 | Phylogenetic relationships between tomato and Arabidopsis fructokinases. Phylogenetic evolutionary analysis was conducted using MEGA version 4 (Tamura et al., 2007). This phylogenetic tree is based on the following protein sequences: SIFRK1 (NP_001233893), SIFRK2 (NP_001233888), SIFRK3 (NP_001234396), SIFRK4 (NP_001234206), At5g51830 (NP_199996), At1g66430 (NP_564875), At4g10260 (NP_192764), At3g59480 (NP_191507), At1g06030 (NP_172093), At1g06020 (NP_172092), and At2g31390 (NP_180697). 